\title{
Relationships between phenylalanine levels, intelligence and socioeconomic status of patients with phenylketonuria
}

\author{
Isabel Pimenta Spínola Castro, ${ }^{1}$ Juliana Martins Borges, ${ }^{2}$ Heloísa Alves Chagas, ${ }^{2}$ \\ Jacqueline Tibúrcio, ${ }^{3}$ Ana Lúcia Pimenta Starling, ${ }^{4}$ Marcos José Burle de Aguiar ${ }^{5}$
}

\begin{abstract}
Objectives: To assess intelligence and its relationship with blood phenylalanine concentrations and socioeconomic status in patients with phenylketonuria after 6 to 12 years of treatment.

Methods: Sixty-three children were classified according to phenylalanine levels and socioeconomic status and assessed using the Wechsler Intelligence Scale for Children. The Statistical Package for the Social Sciences (SPSS) was used to analyze phenylalanine; ANOVA was used to analyze intelligence quotients (IQ) and phenylalanine levels; and ordinal logistic regression was used to analyze the likelihood of higher IQ.

Results: The overall IQ scores of $90.5 \%$ of the children were within a range from borderline intellectual deficiency to very high intelligence; for verbal IQ this proportion was $96.8 \%$ and $92.1 \%$ had performance IQ scores within this band. The categories from low to upper-medium socioeconomic status contained $98.4 \%$ of patients' families. The likelihood of having medium to high IQ was 4.29 times greater for children with good phenylalanine control and 4.03 greater for those from higher socioeconomic strata.

Conclusions: Treatment prevented mental retardation in $90.5 \%$ of the patients. Control of phenylalanine levels and higher socioeconomic status were associated with higher IQ scores.
\end{abstract}

J Pediatr (Rio J). 2012;88(4):353-6: Phenylketonuria, intelligence, cognition, phenylalanine.

\section{Introduction}

Phenylketonuria (PKU) is an autosomal recessive disease that causes mental retardation if left untreated. Treatment consists of a special diet, associated with an amino acid mixture that is either free from, or very low in, phenylalanine (Phe). ${ }^{1,2}$ Neonatal screening makes early diagnosis and treatment possible, which averts mental retardation that is of varying intensity, but irreversible. ${ }^{2}$
The Center for Newborn Screening and Genetic Diagnostics (NUPAD - Núcleo de Ações e Pesquisa em Apoio Diagnóstico) from the Faculty of Medicine of the Federal University of Minas Gerais State is the center of excellence responsible for the Minas Gerais State Newborn Screening Program (PETN-MG - Programa Estadual de Triagem Neonatal de Minas Gerais); and the Special Genetics Service at the

1. Psychologist. MSc, Saúde da Criança e do Adolescente, Universidade Federal de Minas Gerais (UFMG), Belo Horizonte, MG, Brazil.

2. Psychologist, UFMG, Belo Horizonte, MG, Brazil.

3. MSc, Estatística, UFMG, Belo Horizonte, MG, Brazil.

4. PhD. Adjunct professor, Departamento de Pediatria, Faculdade de Medicina, UFMG, Belo Horizonte, MG, Brazil.

5. PhD. Associate professor, Departamento de Pediatria, Faculdade de Medicina, UFMG, Belo Horizonte, MG, Brazil.

No conflicts of interest declared concerning the publication of this article.

Suggested citation: Castro IP, Borges JM, Chagas HA, Tibúrcio J, Starling AL, de Aguiar MJ. Relationships between phenylalanine levels, intelligence and socioeconomic status of patients with phenylketonuria. J Pediatr (Rio J). 2012;88(4):353-6.

Manuscript submitted Sep 8 2011, accepted for publication Jan 42012.

http://dx.doi.org/10.2223/JPED.2175 
Hospital das Clínicas (SEGHC - Serviço Especial de Genética do Hospital das Clínicas) at UFMG, in collaboration with NUPAD, is responsible for treating PKU in the Brazilian state of Minas Gerais, which has an incidence of approximately $1 / 21,000$ newborn infants. ${ }^{3}$

Cognitive assessment is necessary even when PKU patients have received treatment early, since intellectual performance may be affected and scores for certain areas may be lower. ${ }^{4}$ There are reports of an association between blood Phe concentration and intellectual capacity and academic performance. ${ }^{4-6}$ The majority of these studies enrolled small numbers of patients and compared them with healthy controls and did not establish relationships between Phe concentrations and socioeconomic status and patients' performance in intelligence tests.

The objective of this study was to investigate the relationships among intelligence, disease control (Phe levels) and socioeconomic status among patients aged 6 to 12 years who were diagnosed with PKU and treated early by a single multidisciplinary team, in order to contribute to understanding of the effects these factors have on PKU patients treated early. Overall intelligence quotient (IQ), performance IQ, verbal IQ, blood Phe concentrations and socioeconomic status were analyzed for $90 \%$ of the PKU patients in this age group resident in the state of Minas Gerais, which has around 19 million inhabitants.

\section{Patients and methods}

Seventy 6 to 12-year-old phenylketonuria patients treated at SEGHC were invited to take part in the study.

Inclusion criteria were: patients receiving treatment at SEGHC, who had started treatment within 90 days; were free from other diseases that compromise cognitive development; and whose parents or legal guardians signed free and informed consent forms.

The exclusion criteria were no free and informed consent form; child unwilling to take part; and missing Phe test result information for patients transferred from other services.

Sixty-three patients met both sets of criteria and took part in the study. There was no sample size calculation because the study took in all patients on treatment in Minas Gerais state.

Intelligence was assessed using the Wechsler Intelligence Scale for Children (WISC-III), which provides an overall IQ, a verbal IQ and a performance IQ. ${ }^{7}$

A socioeconomic assessment developed by the Social Work Department of the Psychology Clinic at the Universidade de São Paulo's Institute of Psychology was also administered. 8

The SEGHC protocol specifies weekly Phe tests for the first 6 months of life, fortnightly tests from 6 to 12 months and monthly tests thereafter. From 2 years onwards the monthly tests can be reduced to bimonthly, depending on adherence to treatment.

Treatment was classified into one of three categories on the basis of mean total Phe concentration (in $\mu \mathrm{mol} / \mathrm{L}$ ) and age in years:

- Adequate: under 6 years: $\leq 360 ; 6$ to 10 years: $\leq 480$; over 10 years: $\leq 600$.

- Regular: under 6 years: $>360$ and $\leq 480$; 6 to 10 years: $>480$ and $\leq 600$; over 10 years: $>600$ and $\leq 700$.

- Inadequate: under 6 years: $>480$; 6 to 10 years: > 600; over 10 years: > 700 .

Blood Phe levels were analyzed using the Statistical Package for the Social Sciences (SPSS Inc., Chicago, IL) version 13. ANOVA was used to test for differences between mean WISC-III scores and mean blood Phe classifications. An ordinal logistic regression model was used to assess associations between intellectual performance, Phe concentrations and socioeconomic status. The threshold for statistical significance was set at $5 \%(p<0.05)$.

This study was approved by the Research Ethics Committee at UFMG.

\section{Results}

The patients were classified as follows for overall intelligence: six (9.5\%) were intellectually deficient; 11 (17.5\%) were borderline; eight $(12.7 \%)$ had medium-low intelligence; 25 (39.7\%) had medium; four (6.3\%) had medium-high; six (9.5\%) had high; and three $(4.8 \%)$ had very high intelligence.

Their verbal IQ scores were classified as follows: two $(3.2 \%)$ were intellectually deficient; five (7.9\%) were borderline; seven (11.2\%) had medium-low verbal intelligence; 29 (46\%) had medium; 10 (15.9\%) had medium-high; four (6.3\%) had high; and six (9.5\%) had very high verbal intelligence.

According to their performance IQ scores, the patients were classified as follows: five (7.9\%) were intellectually deficient; eight (12.7\%) were borderline; 16 (25.4\%) had medium-low performance intelligence; 23 (36.5\%) had medium; eight (12.7\%) had medium-high; two (3.2\%) had high; and one (1.6\%) had very high performance intelligence.

The socioeconomic assessment classified patients' families into the following categories: six $(9.5 \%)$ were low status; 38 (60.4\%) were low-upper; 18 (28.6\%) mid-lower; and one $(1.6 \%)$ was middle status. None of the families were high socioeconomic status.

There was an association between children's Phe control classifications and their WISC-III overall IQ, verbal IQ and performance IQ results (Table 1 ). 
Table 1 - Association between WISC-III overall IQ and disease control classified by mean blood Phe levels

\begin{tabular}{|c|c|c|c|c|c|c|}
\hline Variable & $\begin{array}{l}\text { Classification } \\
\text { (overall mean) }\end{array}$ & Mean + SDA & Median & Minimum & Maximum & $\mathbf{p}^{*}$ \\
\hline \multirow[t]{3}{*}{ Verbal IQ } & Inadequate & $91.5+17.0$ & 90.5 & 61.0 & 131.0 & 0.001 \\
\hline & Regular & $105.9+17.3$ & 104.5 & 74.0 & 137.0 & \\
\hline & Adequate & $110.6+16.1$ & 108.0 & 83.0 & 145.0 & \\
\hline \multirow[t]{3}{*}{ Performance IQ } & Inadequate & $83.8+15.1$ & 84.0 & 54.0 & 121.0 & $<0.001$ \\
\hline & Regular & $97.0+14.8$ & 98.0 & 71.0 & 132.0 & \\
\hline & Adequate & $101.7+11.4$ & 100.0 & 82.0 & 121.0 & \\
\hline \multirow[t]{3}{*}{ IQ total } & Inadequate & $86.7+17.0$ & 87.0 & 54.0 & 129.0 & $<0.001$ \\
\hline & Regular & $101.8+16.4$ & 103.5 & 70.0 & 136.0 & \\
\hline & Adequate & $106.8+13.9$ & 104.0 & 85.0 & 137.0 & \\
\hline
\end{tabular}

$\mathrm{IQ}=$ intelligence quotient; $\mathrm{Phe}=$ phenylalanine; SD = standard deviation; WISC-III = Wechsler Intelligence Scale for Children.

${ }^{*} p \leq 0.05$.

Mean IQs were stratified. Children with adequate control had higher results for all three IQ scores than those with regular control and these in turn had higher results than those with inadequate control (Table 1).

The ordinal logistic regression showed that children classified as regular according to Phe concentrations were 3.86 times more likely to have high or medium IQ than those classified as having inadequate control. Children classified as having adequate control were 4.29 times more likely to have high or medium IQ than those classified as having inadequate control. (Table 2).

Children from medium socioeconomic status families were 4.03 times more likely to have high or medium IQ when compared to children from low socioeconomic status families (Table 2).

\section{Discussion}

Neonatal screening demands constant reassessment of its own results. ${ }^{9}$ The most important aspect in PKU cases is intelligence, since the primary objective of treatment is to prevent mental retardation. ${ }^{10}$ We reviewed the literature and were unable to find another single-center study with a larger patient sample - only multicenter studies have investigated larger numbers of patients. ${ }^{11}$ Specifically within Brazilian literature, we only found studies of specific aspects of intelligence, one of which was conducted at our own service; ${ }^{5}$ but none of them had similar study designs.

We chose the WISC-III test because it is one of the most widely-used intelligence tests worldwide ${ }^{6}$ and has been standardized and validated for the Brazilian population. ${ }^{7}$

Table 2 - Proportional odds model with the response category overall IQ score during the study period with relation to Phe blood concentration control classification and socioeconomic status of patients' families

\begin{tabular}{|c|c|c|c|c|}
\hline Covariable & Categories & OR & $95 \% \mathrm{CI}$ & $\mathbf{p}$ \\
\hline \multirow[t]{3}{*}{ Overall mean Phe ${ }^{* \dagger}$} & Inadequate & 1.00 & - & - \\
\hline & Regular & 3.86 & $1.18-12.67$ & 0.026 \\
\hline & Adequate & 4.29 & $1.05-17.48$ & 0.042 \\
\hline \multirow[t]{2}{*}{ Socioeconomic status $^{\dagger}$} & Low & 1.00 & - & - \\
\hline & Mid & 4.03 & $1.23-13.23$ & 0.022 \\
\hline
\end{tabular}

$95 \% \mathrm{Cl}=95 \%$ confidence interval; $\mathrm{IQ}=$ intelligence quotient; $\mathrm{OR}=$ odds ratio; Phe = phenylalanine.

* During the study period.

$\dagger$ Pearson's test $=0.725$; test of deviance $=0.544$. 
The socioeconomic questionnaire was chosen because it is simple and easy to administer and does not lack any of the relevant data. ${ }^{8}$

Recommended blood Phe levels by age group vary across different European countries and the United States. ${ }^{12,13}$ At SEGHC, several different protocols were used to create a classification for disease control of children in each age group, with adequate, regular and inadequate categories depending of Phe concentrations and age, as described above.

Sixty-three (90\%) of the 70 patients aged 6 to 12 years on treatment at SEGHC underwent the tests. This is a very significant percentage of the PKU patients in this age group who are on treatment in the state of Minas Gerais, since the state has no other centers that treat PKU.

The best results for patients with good Phe level control are in line with the literature, 6,11 when compared with those with regular or poor control. The fact that these results are stratified, with the highest IQ scores in patients with good control, intermediate scores among those with regular control and lowest scores among those with poor control - shows that even small differences in Phe levels can have detectable repercussions and is evidence in favor of the control classification adopted at SEGHC.

The finding that verbal IQ scores were better than performance IQ scores is similar to reports by other authors, 5,6 who have found that patients with phenylketonuria who receive early treatment have greater difficulty with performance tasks. It has been reported that the frontal area responsible for executing non-verbal tasks demands higher dopamine consumption, which is a neurotransmitter that phenylketonuria patients produce at reduced levels. 6,14

Although the greater part of the families were of low socioeconomic status, this does not appear to introduce bias, since SEGHC is the only PKU treatment center in the state and patients diagnosed in the private system are also referred there. The ordinal logistic regression results showing that higher socioeconomic status was associated with greater likelihood of good scores have also been observed by Azen et al.,11 demonstrating that this factor contributes to intellectual capacity.

The ordinal logistic regression also showed that children with good control were more likely to score higher on the intelligence tests. This was also detected in a review article by Waisbren et al. ${ }^{15}$ who state that excess Phe can compromise information processing, which is a capacity that is directly associated with general intelligence.

While many questions related to the study of intelligence in phenylketonuria patients remain to be answered, this study has demonstrated the role that treatment has to play in prevention of moderate and severe mental retardation and the influence that control of blood Phe levels and socioeconomic status have on the cognitive development of these patients.

\section{References}

1. Dobbelaere D, Michaud L, Debrabander A, Vanderbecken S, Gottrand F, Turck D, et al. Evaluation of nutritional status and pathophysiology of growth retardation in patients with phenylketonuria. J Inherit Metab Dis. 2003;26:1-11.

2. Giugliani L, Sitta A, Vargas CR, Santana-da-Silva LC, Nalin T, Saraiva-Pereira ML, et al. Tetrahydrobiopterin responsiveness of patients with phenylalanine hydroxylase deficiency. J Pediatr (Rio J). 2011;87:245-51.

3. MartinsSR. Incidência defenilcetonúriaeoutrashiperfenilalaninemias no Estado de Minas Gerais: dados do Programa Estadual de Triagem Neonatal [dissertação]. Belo Horizonte: Universidade Federal de Minas Gerais; 2005.

4. Shalev RS, Auerbach J, Manor O, Gross-Tsur V. Developmental dyscalculia: prevalence and prognosis. Eur Child Adolesc Psychiatry. 2000;9:II58-64.

5. Malloy-Diniz LF, Cardoso-Martins C, Carneiro KC, Cerqueira MM, Ferreira AP, Aguiar MJ, et al. Executive functions in children with phenylketonuria: variations as a function of phenilalanine plasm level. Arq Neuropsiquiatr. 2004;62:473-9.

6. Huijbregts $S C$, de Sonneville LM, Licht $R$, van Spronsen FJ, Verkerk PH, Sergeant JA. Sustained attention and inhibition of cognitive interference in treated phenylketonuria: associations with concurrent and lifetime phenylalanine concentrations. Neuropsychologia. 2002;40:7-15.

7. Wechsler D. WISC-III: escala de inteligência para crianças - manual. Adaptação e padronização brasileira de Vera Lúcia Marques de Figueiredo. 3a edição. São Paulo: Casa do Psicólogo; 2002.

8. Souza MA. O funcionamento intelectual de drogadictos através do Rorschach. Bol Psicol. 1995;103:105-24.

9. Leão LL, Aguiar MJ. Newborn screening: what pediatricians should know. J Pediatr (Rio J). 2008;84:S80-90.

10. Gassió R, Fusté E, López-Sala A, Artuch R, Vilaseca MA, Campistol J. School performance in early and continuously treated phenylketonuria. Pediatr Neurol. 2005;33:267-71.

11. Azen CG, Koch R, Friedman EG, Berlow S, Coldwell J, Krause W, et al. Intellectual development in 12-year-old children treated for phenylketonuria. Am J Dis Child. 1991;145:35-9.

12. Blau N, Burton BK, Thöny B, van Spronsen FJ, Waisbren S. Phenylketonuria and $\mathrm{BH} 4$ deficiences. Bremen: UNI-MED Verlag; 2010.

13. Blau $N$, Bélanger-Quintana $A$, Demirkol $M$, Feillet $F$, Giovannini $M$, MacDonald $A$, et al. Management of phenylketonuria in Europe: survey results from 19 countries. Mol Genet Metab. 2010;99:109-15.

14. Neisser U, Boodoo G, Bouchard T, Boykin AW, Brody N, Ceci $\mathrm{S}$, et al. Intelligence: knowns and unknowns. Am Psychol. 1996;51:77-101.

15. Waisbren SE, Brown MJ, de Sonneville LM, Levy HL. Review of neuropsychological functioning in treated phenylketonuria: an information processing approach. Acta Paediatr Suppl. 1994;407:98-103.

Correspondence:

Marcos José Burle de Aguiar

Rua Timbiras, 659/1001

CEP 30140-060 - Funcionários, Belo Horizonte, MG - Brazil

Tel.: +55 (31) 3274.3453

E-mail: aguiarmr@terra.com.br 